\title{
Pulmonary function testing in children's interstitial lung disease
}

\author{
Astrid Madsen Ring ${ }^{1,13}$, Julia Carlens ${ }^{2,13}$, Andy Bush ${ }^{3,4}$, \\ Silvia Castillo-Corullón (10 ${ }^{5}$, Salvatore Fasola ${ }^{6}$, Mirella Piera Gaboli ${ }^{7}$, \\ Matthias Griese ${ }^{8}$, Vaclav Koucky ${ }^{9}{ }^{9}$, Stefania La Grutta ${ }^{6}$, Enrico Lombardi ${ }^{10}$, \\ Marijke Proesmans ${ }^{11}$, Nicolaus Schwerk ${ }^{2}$, Deborah Snijders ${ }^{12}$, \\ Kim Gjerum Nielsen ${ }^{1,14}$ and Frederik Buchvald ${ }^{1,14}$
}

Affiliations: ${ }^{1}$ Paediatric Pulmonary Service, Dept of Paediatrics and Adolescent Medicine, Copenhagen University Hospital, Rigshospitalet, Danish PCD \& chILD Centre, CF Centre Copenhagen, Copenhagen, Denmark. ${ }^{2}$ Clinic for Paediatric Pneumology, Allergology and Neonatology, Medizinische Hochschule Hannover Zentrum fur Kinderheilkunde und Jugendmedizin, Hannover, Germany. ${ }^{3}$ Paediatrics and Paediatric Respiratory Medicine, Imperial College London, London, UK. ${ }^{4}$ Paediatric Respiratory Medicine, Royal Brompton and Harefield NHS Foundation Trust, London, UK. ${ }^{5}$ Unidad de Neumología infantil y Fibrosis quística, Hospital Clínico Universitario de Valencia, Valencia, Spain. 'Institute of Biomedical Research and Innovation, National Research Council of Italy, Palermo, Italy. ${ }^{7}$ Neumologia Infantil y Unidad de Cuidados Intensivos Pediatricos, Hospital Universitario Salamanca, Salamanca, Spain. ${ }^{8}$ University Hospital of Munich, Dr. von Hauner Children's Hospital, German Center for Lung Research (DZL), Munich, Germany. 'Dept of Paediatrics, Univerzita Karlova v Praze 2 lekarska fakulta, Praque, Czech Republic. ${ }^{10}$ Pediatric Pulmonary Unit, Anna Meyer Pediatric University-Hospital, Florence, Italy. ${ }^{11}$ Pediatric pulmonology, KUL UZ Gasthuisberg, Leuven, Belgium. ${ }^{12}$ Dept of Pediatrics, University of Padova, Padova, Italy. ${ }^{13}$ Joint first authors. ${ }^{14}$ Joint last authors.

Correspondence: Frederik Buchvald, Danish PCD \& chILD Centre, CF Centre Copenhagen, Paediatric Pulmonary Service, Dept of Pediatrics and Adolescent Medicine, Copenhagen University Hospital, Rigshospitalet, Blegdamsvej 9, DK-2100, Copenhagen, Denmark. E-mail: fbuchvaldadadlnet.dk

@ERSpublications

Pulmonary function testing may be useful in different stages of management of children with suspected or confirmed chILD but this literature search revealed only a limited number of papers published in the last three decades. https://bit.ly/3cs0uZr

Cite this article as: Ring AM, Carlens J, Bush A, et al. Pulmonary function testing in children's interstitial lung disease. Eur Respir Rev 2020; 29: 200019 [https://doi.org/10.1183/16000617.0019-2020].

ABSTRACT The use of pulmonary function tests (PFTs) has been widely described in airway diseases like asthma and cystic fibrosis, but for children's interstitial lung disease (chILD), which encompasses a broad spectrum of pathologies, the usefulness of PFTs is still undetermined, despite widespread use in adult interstitial lung disease.

A literature review was initiated by the COST/Enter chILD working group aiming to describe published studies, to identify gaps in knowledge and to propose future research goals in regard to spirometry, wholebody plethysmography, infant and pre-school PFTs, measurement of diffusing capacity, multiple breath washout and cardiopulmonary exercise tests in chILD. The search revealed a limited number of papers published in the past three decades, of which the majority were descriptive and did not report pulmonary function as the main outcome.

PFTs may be useful in different stages of management of children with suspected or confirmed chILD, but the chILD spectrum is diverse and includes a heterogeneous patient group in all ages. Research studies in well-defined patient cohorts are needed to establish which PFT and outcomes are most relevant for diagnosis, evaluation of disease severity and course, and monitoring individual conditions both for improvement in clinical care and as end-points in future randomised controlled trials.

This article has supplementary material available from err.ersjournals.com

Provenance: Submitted article, peer reviewed.

Received: 23 Jan 2020 | Accepted after revision: 11 April 2020

Copyright $\odot$ ERS 2020. This article is open access and distributed under the terms of the Creative Commons Attribution Non-Commercial Licence 4.0. 


\section{Introduction}

Children's interstitial lung disease (chILD) comprises over 200 different disease entities. All these conditions are rare and, although diffuse, they differ from diffuse lung diseases (DLD) in adulthood. A classification system was proposed separating entities primarily seen in infants and preschool children from those occurring at any age $[1,2]$. chILD is a basket of clinical entities and for many of the conditions no specific diagnostic tests exist, and evidence-based treatment is lacking. However, a combination of clinical symptoms and signs (such as tachypnoea, hypoxaemia, dry cough, crackles, digital clubbing), radiographic abnormalities, lung biopsy findings or genetic testing may lead to the diagnosis of a definite disease entity, but many diagnoses are nonspecific and purely descriptive [3].

Pulmonary function testing is a cornerstone in the evaluation of respiratory disease to obtain objective measures for the initial work up, diagnosis and follow-up [3, 4]. However, there are very few studies concerning the usefulness (feasibility, monitoring and treatment evaluation) of the various pulmonary function tests (PFTs) in chILD. The purpose of this narrative literature review was to give an overview of the different PFTs that may be relevant in the diagnosis and monitoring of patients with chILD in different age groups and present relevant standard operating procedures (SOPs) and age-related reference material. The further purpose was to present results from previously published studies in which PFTs were performed in chILD patients.

This literature review of lung function testing in chILD was initiated by the COST Action "Enter chILD" working group (www.cost.eu/actions/CA16125) to explore existing studies in the field and conduct a narrative review, with a view to identifying the gaps in current knowledge and to propose future research goals.

\section{Methods}

A literature search was performed in PubMed for original articles with a specific focus on lung function testing in children with interstitial/diffuse parenchymal lung diseases according to the classifications by DeUTSCH et al. [1] and GRIESE et al. [2]. The search also included SOPs and age-related reference materials for different PFTs relevant in the paediatric age group. The literature search process and inclusion and exclusion criteria are described further online in the supplementary material.

\section{Lung function tests}

A summary of all included PFTs is presented in table 1.

\section{Spirometry and whole-body plethysmography}

Spirometry is used to detect restrictive and obstructive impairment. Main outcomes are the forced vital capacity (FVC) and forced expiratory volume in $1 \mathrm{~s}\left(\mathrm{FEV}_{1}\right)$ (for preschool children: $0.5 \mathrm{~s}\left(\mathrm{FEV}_{0.5}\right)$ or $0.75 \mathrm{~s}$ $\left(\mathrm{FEV}_{0.75}\right)$ ) as well as forced expiratory flows at different lung volumes. The technique is feasible and can be performed quickly in most clinical and outpatient settings from late pre-school age onwards. Disadvantages are the need for active cooperation and the difficulty in performing a maximal and forced expiratory manoeuvre. Falsely low FVC measurements may result from submaximal efforts, and obstructive changes can lead to reduced vital capacity (pseudo-restriction). Spirometry is well standardised and there are international SOPs and reference equations for different ages [15, 24-27]. The 2012 Global Lung Initiative reference equations are one of the most comprehensive datasets but were not available for the majority of reviewed publications [28].

The addition of specific airway resistance $\left(\mathrm{s} R_{\mathrm{aw}}\right)$, airway resistance $\left(R_{\mathrm{aw}}\right)$ and lung volumes (functional residual capacity (FRC), residual volume and total lung capacity (TLC)) using whole-body plethysmography may help to differentiate between restrictive, combined restrictive/obstructive and pseudo-restrictive ventilatory airway disorders [21]. Restrictive lung disease is defined as a TLC below the lower limit of normal. Reference values exist for patients aged $\geqslant 3$ years for $s R_{\mathrm{aw}}$ measured during slightly accelerated tidal breathing [22] and $\geqslant 6$ years for $R_{\mathrm{aw}}$ and lung volumes, which require certain active cooperation with specific respiratory manoeuvres [23].

\section{Infant PFTs}

There are currently five methods for infant pulmonary function testing (iPFT) commercially available for usage in children aged $<2$ years of age. Infant whole-body plethysmography enables measurement of FRC, which is well standardised [5] with published reference values [6, 7], and assessment of $(\mathrm{s}) R_{\mathrm{aw}}$, which is less well standardised. Both tidal volume rapid thoracoabdominal compression (TVRTC) and raised volume thoracoabdominal compression (RVRTC) allow evaluation of forced expiration, providing information about peripheral airway obstruction. RVRTC has been shown to be superior to TVRTC with respect to its sensitivity in wheezing infants and infants with cystic fibrosis (CF) $[45,46]$. Maximal flow at 
TABLE 1 Description of included pulmonary function tests

\begin{tabular}{|c|c|c|c|c|c|}
\hline Technique & Target age group & $\begin{array}{l}\text { Main } \\
\text { outcomes }\end{array}$ & Available SOPs" & $\begin{array}{l}\text { Reference } \\
\text { material }\end{array}$ & Advantages/disadvantages \\
\hline $\begin{array}{l}\text { Infant whole-body } \\
\text { plethysmography }\end{array}$ & Infants $<2-3$ years & $\begin{array}{l}\mathrm{FRC} \\
\mathrm{s} R_{\mathrm{aw}}\end{array}$ & Yes (FRC) [5] & Yes (FRC) $[6,7]$ & $\begin{array}{l}\text { Advantages: possible to obtain simultaneous estimation of lung size } \\
\text { and resistance } \\
\text { Disadvantages: not widely available; time consuming; requires } \\
\text { sedation; } s R_{\text {aw }} \text { less standardised }\end{array}$ \\
\hline $\begin{array}{l}\text { Compliance and resistance } \\
\text { measurement }\end{array}$ & Infants & $\begin{array}{l}\tau_{\mathrm{rs}} \\
C_{\mathrm{rs}} \\
R_{\mathrm{rs}}\end{array}$ & Yes [8] & Yes $[6,9]$ & $\begin{array}{l}\text { Advantages: may quantify restrictive lung disease; can be performed } \\
\text { together with infant whole-body plethysmography } \\
\text { Disadvantages: not widely available; time consuming; requires } \\
\text { sedation }\end{array}$ \\
\hline $\begin{array}{l}\text { Forced expiratory manoeuvres: } \\
\text { RVRTC and TVRTC }\end{array}$ & Infants & $\begin{array}{l}V_{\text {maxFRC }}^{\prime} \\
\text { FVC } \\
\mathrm{FEV}_{0.5} \\
\mathrm{FEF}_{25-75}\end{array}$ & Yes $[10,11]$ & Yes [12-14] & $\begin{array}{l}\text { Advantages: obtains parameters comparable to spirometry; highly } \\
\text { reproducible; validated } \\
\text { Disadvantages: not widely available; time consuming; requires } \\
\text { sedation; RTC less discriminative than RVRTC }\end{array}$ \\
\hline Tidal breathing analysis & $\begin{array}{l}\text { Infants and } \\
\text { pre-school children }\end{array}$ & $\begin{array}{c}V_{\mathrm{T}} \\
\mathrm{RR} \\
t_{\mathrm{PTEF}} / t_{\mathrm{E}}\end{array}$ & Yes [15] & $\begin{array}{c}\text { Yes } \\
0-5 \text { years }[16,17]\end{array}$ & $\begin{array}{l}\text { Advantages: high feasibility in awake infants and pre-schoolers } \\
\text { Disadvantages: sedation is often needed }\end{array}$ \\
\hline$R_{\text {int }}$ & $\begin{array}{l}\text { Pre-school children } \\
\text { and older }\end{array}$ & $R_{\text {int }}$ & Yes [15] & $\begin{array}{c}\text { Yes } \\
2-13 \text { years [18] }\end{array}$ & $\begin{array}{l}\text { Advantages: high feasibility in pre-schoolers } \\
\text { Disadvantages: measures } R_{\text {aw }} \text { only }\end{array}$ \\
\hline Oscillometry & $\begin{array}{l}\text { Pre-school children } \\
\text { and older }\end{array}$ & $\begin{array}{l}R_{\mathrm{rs}} \\
X_{\mathrm{rs}}\end{array}$ & Yes [15] & $\begin{array}{c}\text { Yes (from } 2 \text { years) } \\
{[19,20]}\end{array}$ & $\begin{array}{l}\text { Advantages: high feasibility in pre-schoolers; measures airway and } \\
\text { lung tissue properties } \\
\text { Disadvantages: may be experienced as unpleasant; requires several } \\
\text { repetitions }\end{array}$ \\
\hline Whole body plethysmography & $\begin{array}{l}\text { Pre-school children } \\
\text { and older }\end{array}$ & $\begin{array}{l}\text { sRaw } \\
\text { Raw } \\
\text { FRC } \\
\text { RV } \\
\text { TLC }\end{array}$ & Yes [21] & Yes $[22,23]$ & $\begin{array}{l}\text { Advantages: lung volume measurements; sRaw for pre-schoolers/all } \\
\text { ages (does not require "panting"); can be combined with spirometry } \\
\text { manoeuvre; available in most centres } \\
\text { Disadvantages: } \\
\text { Volume measurements for school children requires maximal in-/ } \\
\text { expiration; cooperation is needed }\end{array}$ \\
\hline Spirometry & $\begin{array}{l}\text { Pre-school children } \\
\text { and older }\end{array}$ & $\begin{array}{l}\mathrm{FEV}_{1} \\
\mathrm{FEV}_{0.5} \\
\mathrm{FEV}_{0.75} \\
\mathrm{FVC} \\
\mathrm{FEV}_{1} / \mathrm{FVC} \\
\mathrm{FEF}_{25-75}\end{array}$ & Yes $[15,24,25]$ & $\begin{array}{l}\text { Yes (from } 3 \text { years) } \\
{[26-28]}\end{array}$ & $\begin{array}{l}\text { Advantages: feasible and well standardized technique; available in all } \\
\text { centres; fast to perform } \\
\text { Disadvantages: requires forced expiration }\end{array}$ \\
\hline
\end{tabular}




\begin{tabular}{|c|c|c|c|c|c|}
\hline Technique & Target age group & $\begin{array}{l}\text { Main } \\
\text { outcomes }\end{array}$ & Available SOPs ${ }^{\#}$ & $\begin{array}{l}\text { Reference } \\
\text { material }\end{array}$ & Advantages/disadvantages \\
\hline Diffusing capacity & $\begin{array}{l}\text { School children and } \\
\text { older }\end{array}$ & $\begin{array}{l}T_{\mathrm{LCO}} \\
\mathrm{K}_{\mathrm{CO}} \\
\mathrm{TLC} \\
\mathrm{VC}\end{array}$ & Yes [30] & $\begin{array}{c}\text { Yes (from } 5 \text { years) } \\
{[31-35]}\end{array}$ & $\begin{array}{l}\text { Advantages: feasible and well standardised technique; available in } \\
\text { most centres } \\
\text { Disadvantages: measurement of haemoglobin is required }\end{array}$ \\
\hline MBW & All ages & $\begin{array}{l}\mathrm{LCl} 2,5 \\
\mathrm{~S}_{\text {cond }} \\
\mathrm{S}_{\text {acin }} \\
\mathrm{FRC}_{\text {gas }}\end{array}$ & Yes $[37,68]$ & $\begin{array}{l}\text { Yes, but only for } \\
\mathrm{SF}_{6} \text { MBW [8-40] }\end{array}$ & $\begin{array}{l}\text { Advantages: only tidal breathing is required; the technique is available } \\
\text { for all ages } \\
\text { Disadvantages: reference material for } \mathrm{N}_{2} \mathrm{MBW} \text { is missing; time } \\
\text { consuming in advanced stages of the disease; the value of } \mathrm{N}_{2} \mathrm{MBW} \\
\text { in infants is still not clear }\end{array}$ \\
\hline 6-minute walk test & Pre-school and older & 6-MWD & Yes [72] & $\begin{array}{c}\text { Yes (from } 3 \text { years) } \\
\text { [73] }\end{array}$ & $\begin{array}{l}\text { Advantages: does not require any specific equipment } \\
\text { Disadvantages: cannot distinguish cardiac/muscular/ pulmonary } \\
\text { impairment }\end{array}$ \\
\hline Maximal exercise test & School age and older & $\begin{array}{l}V_{\mathrm{O}_{2}}^{\prime} \text { peak } \\
\mathrm{HR}_{\max } \\
\mathrm{RER} \\
V_{\mathrm{E}}^{\prime} \\
W_{\max }\end{array}$ & Yes $[74,75]^{\pi}$ & Yes [78] & $\begin{array}{l}\text { Advantages: a more precise estimate of the patient's maximal } \\
\text { cardiopulmonary capacity } \\
\text { Disadvantages: requires specific equipment; requires motivation from } \\
\text { the patient; more risk involved than in submaximal tests; requires } \\
\text { trained staff; skills needed to clarify cardiac/muscular/ pulmonary } \\
\text { impairment }\end{array}$ \\
\hline \multicolumn{6}{|c|}{ 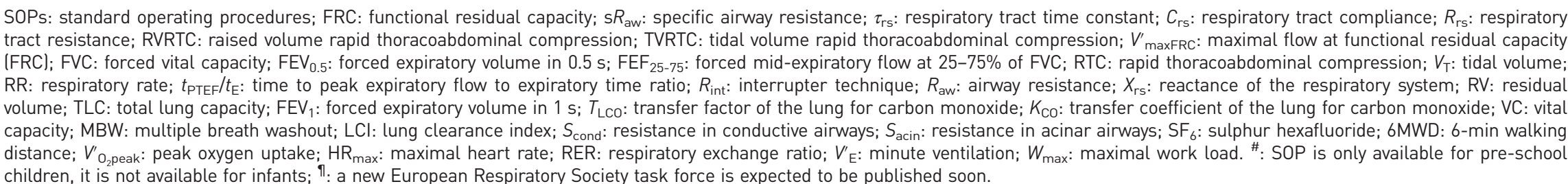 } \\
\hline
\end{tabular}


FRC is the main TVRTC outcome parameter, while FVC, $\mathrm{FEV}_{0.5}$ and forced mid-expiratory flow may be derived from RVRTC. These methods are well standardised [10,11] and reference values have been published [12-14]. Measurement of passive respiratory tract mechanics is used to assess compliance and resistance of the entire respiratory system noninvasively during spontaneous breathing. SOP [8] and reference values $[6,9,47]$ are available. Tidal breath analysis utilises flow and volume measurements to calculate minute ventilation, tidal volume $\left(V_{\mathrm{T}}\right)$, respiratory rate $(\mathrm{RR})$ and various indices of breath timing (for example, inspiratory time to expiratory time ratio $\left(t_{\mathrm{I}} / t_{\mathrm{E}}\right)$ and time to peak expiratory flow/ $t_{\mathrm{E}}$ ratio) $[48,49]$. The multiple breath inert gas washout test (MBW), which may also be adapted for infants, is discussed in the following sections. iPFT has been demonstrated to provide clinically relevant information in infants with chronic lung disease of prematurity [50-52], CF [53-55] and recurrent wheezing [56]. Limitations of iPFT include the need for specialised equipment and trained staff. Usually sedation is needed (chloral hydrate or triclofos) to ensure regular breathing and enable a face mask to be tolerated, which makes iPFT time and resource intensive.

\section{Tidal breathing indices, interrupter technique and forced oscillation technique}

Tidal breathing indices, the interrupter technique $\left(R_{\text {int }}\right)$ and the forced oscillation technique (FOT) can all be used to measure lung function in pre-school children. Since the tests are executed during tidal breathing, they are quick to perform, and also equipment is commercially available. Technical recommendations have recently been published for pre-school children [15] and, for FOT, also for adults [19]. Several indices can be measured during tidal breathing: $R R, V_{\mathrm{T}}, t_{\mathrm{I}}$ and $t_{\mathrm{E}}$. Reference values have been reported for these indices, although they are laboratory specific $[16,17]$. The need to reach a stable and regular breathing pattern is the main technical limitation of these methods. An irregular breathing pattern may increase the intra-individual variability, thus limiting reproducibility and suitability for long-term follow-up. $R_{\text {int }}$ is based on the assumption that during a sudden flow interruption during tidal breathing, mouth pressure equilibrates with alveolar pressure and resistance can hence be calculated, i.e. dividing mouth pressure by the flow measured just before (classical technique) or just after (opening technique) the interruption [15]. Several reference values have been published [57-59], some of which were recently unified by the Asthma UK Initiative [18]. FOT is based on the principle that respiratory impedance can be calculated by measuring the changes in mouth pressure and flow generated by small pressure oscillations at a low frequency applied to the airways [15, 19]. Respiratory impedance can be divided into resistance of respiratory system representing the frictional pressure loss, and respiratory system reactance, which at low frequencies represents the compliance (distensibility) of the respiratory system and at high frequencies inertance. Low frequency oscillations $(4-48 \mathrm{~Hz})$ are generated by a loudspeaker and can be based on sinusoidal waves or impulses, both as single-frequency or composite signals. Reference values starting at the age of 2 years have been published for both techniques $[15,19,20]$.

\section{Diffusing capacity measurement}

The transfer factor of the lung for carbon monoxide $\left(T_{\mathrm{LCO}}\right)$ measures the ability of the lungs to transfer gas from inhaled air into the red blood cells in the pulmonary capillaries, and can be used to monitor disease progression and response to treatment in diffuse lung disease [60]. $T_{\mathrm{LCO}}$ changes with the level of haemoglobin, lung volume, carboxyhaemoglobin levels and altitude, and adjustments for these factors, in particular haemoglobin, may be needed prior to interpreting results $[61,62]$. In DLD with diffuse loss of lung units, the transfer coefficient of the lung for carbon monoxide $\left(K_{\mathrm{CO}}\right)$ is reduced due to the reduced size of the alveolar-capillary bed, but the alveolar volume $\left(V_{\mathrm{A}}\right)$ may also be reduced because of reduced lung compliance, causing a markedly reduced $T_{\mathrm{LCO}}\left(T_{\mathrm{LCO}}=K_{\mathrm{CO}} \times V_{\mathrm{A}}\right)$. Hence the relative changes in $K_{\mathrm{CO}}$ and $T_{\mathrm{LCO}}$ depend on the nature and severity of the condition studied. $T_{\mathrm{LCO}}$ may be increased if there has been recent pulmonary haemorrhage [63], as in idiopathic pulmonary haemosiderosis. In most cases of asthma, $T_{\mathrm{LCO}}$ is normal but may be increased. This is thought to be due to increased changes in pleural pressure needed to overcome airflow obstruction having the secondary effect of augmenting venous return and thus increasing pulmonary blood volume $[64,65]$. It is important to notice that $T_{\text {LCO }}$ may be reduced in several other conditions only loosely related to a pulmonary parenchymal disease, including hepatopulmonary syndrome, pulmonary embolic disease and primary pulmonary hypertension, or affected by factors that limit chest expansion, such as muscle weakness or chest wall deformity [66].

$T_{\mathrm{LCO}}$ is, in general, a feasible, rapid and non-expensive test to perform with limited discomfort for the patient, whether by single breath or rebreathing. The technique most commonly used is the single breath method which requires a $10 \mathrm{~s}$ breath hold and may be difficult for preschool children and for very tachypnoeic patients. Methods have been developed for measuring single breath $T_{\mathrm{LCO}}$ in infants and toddlers, but these are not widely used or routinely available $[29,67]$. 
Some equipment is unable to measure $T_{\mathrm{LCO}}$ if the patient's vital capacity is $<1.0 \mathrm{~L}$ [30]. There is a SOP from the European Respiratory Society (ERS)/American Thoracic Society (ATS) task force [30], and different reference values in children have been published [31-34]. In 2017 the Global Lung Function Initiative published their reference material for patients aged 5-85 years [35].

\section{MBW}

The MBW test offers important insights into any non-uniformity of gas mixing, predominantly in the distal, airways. The test is performed during tidal breathing via a mouthpiece or facemask. The standard MBW index is the lung clearance index (LCI), which reflects overall ventilation distribution inhomogeneity. Resistance in conductive airways $\left(S_{\text {cond }}\right)$ and resistance in acinar airways primarily reflect heterogeneity in the conductive (airway generation 8-16) and acinar (airway generation 17-23+) lung zones, respectively [68].

MBW has primarily been used in a research setting and most published MBW studies have been conducted in children with CF $[69,70]$, where the technique has been shown to be an earlier and more sensitive indicator than spirometry of pulmonary disease and its progression [71]. Commercially available equipment has facilitated distribution to more centres over recent years and made the method more applicable in a clinical setting. The use of MBW indices as an outcome measure is considered attractive because the technique requires only the passive co-operation of the child. MBW testing is feasible even in infants $[36,69]$ and SOPs covering all age groups exist [37,68]. A limitation is that sedation may be needed in infants and small toddlers and leaks or irregular breathing patterns (including coughing, swallowing or sighing) can impair test quality. Different reference ranges have been published [39,40] but they are mainly based on the sulfur hexafluoride technique and may be laboratory specific, and to date no robust all-age nitrogen MBW reference material exists. LCI normal values are largely independent of age and height, making it promising for long-term follow-up; however, under the age of 6 years, LCI seems to be inversely correlated with height [40]. Studying local healthy subjects is recommended to generate comparator data until robust device-specific reference equations are published for commercial systems [68].

\section{Exercise testing}

Exercise testing measures physical capacity and is measured by a submaximal or maximal method. In this review we have focused on the 6-min walk test $(6 \mathrm{MWT})$ and peak oxygen uptake $\left(V^{\prime} \mathrm{O}_{2}\right.$ peak $)$, although other well-described tests are available, e.g. the step test [41]. The 6MWT is a standardised exercise test which reflects impairments in functional capacity during submaximal effort. Outcome measures are the distance walked on a flat surface in $6 \mathrm{~min}(6 \mathrm{MWD})$ as well as heart rate, oxygen saturation and level of exhaustion and breathlessness after self-paced walking. There is an ATS guideline and reference values for children aged $\geqslant 3$ years $[72,73]$. The test is easy to perform without specialised equipment even in severely ill patients, but it does not allow differentiation of exercise limitations caused by cardiac or pulmonary impairments, e.g. from joint immobility or reduced muscle strength.

$V^{\prime} \mathrm{O}_{2}$ peak is measured during a cardiopulmonary exercise test (CPET) and is often assessed using a graded exercise test until exhaustion while measurements of pulmonary gas exchange are made. $V^{\prime}{ }_{\mathrm{O}_{2}}$ peak may be defined as the maximum capacity to uptake and transport oxygen in the pulmonary and cardiovascular system, and of the capacity of the exercising muscles to utilise oxygen. When performing a direct measurement of $V^{\prime}{ }_{\mathrm{O}_{2} \text { peak }}$, the test must be conducted using a treadmill or a cycle ergometer, but $V^{\prime} \mathrm{O}_{2}$ peak can also be estimated from field tests like the 6MWT [42]. In $\mathrm{CF}, V_{\mathrm{O}_{2} \text { peak }}^{\prime}$ is significantly correlated with survival and quality of life leading to recommendations that it should be part of the annual assessment [43]. ERS and ATS statements for conducting CPET in patients with lung diseases have been published $[74,75]$, but without a specific paediatric focus, and a new ERS statement on standardisation of CPET in chronic lung diseases and how to report outcomes is expected to be published in the near future. Several protocols for cardiopulmonary function testing have been published, but the protocols of GODFREY [76] and BRUCE et al. [44] are most frequently used for the cycle ergometer and the treadmill test, respectively. Several reference equations have been published and it is important to standardise testing using the procedures and methodology of the reference values used as comparators [77, 78].

\section{Results}

The results from the literature searches are listed in table $\mathrm{S} 1$ and are summarised for each of the different lung function tests in tables S2-S7. In total, 48 studies were included. The diseases most studied are hypersensitivity pneumonitis (HP), post-infectious bronchiolitis obliterans (PIBO) and rheumatological diseases which may reflect that they are more common in older children. 


\section{Surfactant disorders}

Clinical utility of iPFT in two patients with different surfactant protein C (SFTPC) mutations (p.173T and p.138F) was demonstrated in a case report [79]. In both patients, a restrictive pattern of impairment was demonstrated, which improved with hydroxychloroquine treatment.

Spirometry was conducted in two studies. One study from 1994 included seven patients with histologically confirmed interstitial lung disease (six children with desquamative interstitial pneumonitis and one with chronic interstitial pneumonitis) [80], and follow-up was reported in 2014 [81] with measurements of spirometry, body plethysmography and $T_{\mathrm{LCO}}$. Five of the seven patients survived and were diagnosed with SFTPC gene mutations ( $p .173 T: n=3 ; p .138 F: n=1 ; p . V 39 L: n=1$ ) and two died, one from respiratory failure, a patient who had a very low FVC at the time of diagnosis (26\% predicted). At the last follow-up of the remaining five patients (aged 28-37 years), three patients had normal FVC, TLC and $T_{\mathrm{LCO}}$ whereas two had a moderately low FVC (65\% and $46 \%$, respectively). The surviving patient with the worst lung function at age 7 years (time of first publication) showed most decline in spirometry at follow-up. $T_{\text {LCO }}$ was also performed at the two follow-up visits [80]: in $1994 T_{\mathrm{LCO}}$ was $>90 \%$ pred in all four patients tested while it was clearly reduced in two patients 20 years later ( $42 \%$ and $58 \%$ pred), a sign of deterioration, whereas the other two patients had more stable values around $80 \%$ pred. Interestingly, $V^{\prime}{ }_{\mathrm{O}_{2} \text { peak }} \mathrm{CPET}$ was also performed and long-term follow-up revealed a preserved fitness $\geqslant 79 \%$ pred in three patients after 20 years of disease; two who continued with abnormal FVC and $T_{\mathrm{LCO}}$.

The second study included six out of nine patients with mutations in the ATP binding cassette sub-family A (ABCA3) gene [82] with longitudinal spirometry data with last follow-up at age 8-18 years. The mean $\pm \mathrm{SD}$ FVC was $43.6 \pm 13.9 \%$ and stability was documented during follow-up.

\section{Pulmonary interstitial glycogenosis}

In a case report, a 3-month-old child with pulmonary interstitial glycogenosis (PIG) had a restrictive pattern of functional impairment measured by iPFT [83]. $T_{\text {LCO }}$ was also measured and was markedly reduced but was normalised by steroid treatment, although FVC remained significantly reduced.

\section{Persistent tachypnoea of infancy and neuroendocrine cell hyperplasia of infancy}

Infants with persistent tachypnoea of infancy have a markedly elevated RR with increased work of breathing. If a lung biopsy is performed and hyperplasia of neuroendocrine cells is found, or characteristic computed tomography findings are present, this is termed neuroendocrine cell hyperplasia of infancy (NEHI) or NEHI syndrome, respectively. Two studies in NEHI $[84,85]$ and one including both NEHI and NEHI syndrome (persistent tachypnoea of infancy) patients [86] documented obstructive lung function (peripheral airway obstruction, airflow limitation and air trapping) using RVRTC and infant whole-body plethysmography, without any differences between NEHI and NEHI syndrome. There were no effects of bronchodilator or corticosteroid treatment on clinical symptoms or lung function. Some of the iPFT parameters correlated with follow-up measurements of haemoglobin saturation 6-12 months after the iPFT and with spirometry $4-5$ years later.

HP

PFTs in 17 children and adolescents with HP were reported [87]. Initial spirometry predominantly showed a restrictive pattern (FVC 42.7\% pred, 95\% CI 38.3-47.1; $\mathrm{FEV}_{1}$ 44.2\% pred, 95\% CI 39.1-49.3) and these parameters improved significantly to near a normal level in more than two-thirds of patients after 3 months of avoidance of exposure and treatment with systemic corticosteroids, with further improvement during the following months of treatment. The median number of pulse steroid courses was 15 per patient (range 8 to 34). The same trend was seen with TLC, $T_{\mathrm{LCO}}$ and $T_{\mathrm{LCO}} / V_{\mathrm{A}}$, with all lung function parameters becoming normal within 6 months after completion of treatment. The same group reported long-term follow-up (median period 3.28 years) in 22 patients (median (range) age 16.7 (11.3-26.9) years) up to 10 years after initial diagnosis of HP [88]. Spirometry was stable during follow-up and was normal in $>90 \%$ of patients while body plethysmography showed reduced TLC in 35\% of the cohort (median z-score: -1.68 ).

Two studies revealed $T_{\mathrm{LCO}}$ to be moderately decreased at diagnosis of $\mathrm{HP}$ with mean values of $52 \%$ and $48 \%$, respectively $[87,89]$. $T_{\mathrm{LCO}}$ was found to increase significantly and normalise after 6 months of treatment [87], and a follow-up study found no further change in $T_{\mathrm{LCO}}$ from the end of treatment to last follow-up several years later [88]. $T_{\mathrm{LCO}}$ median z-score was found to be slightly reduced (median z-score: -1.02 ) but very variable between individuals (range -3.49 to 0.45 ). The follow-up study revealed abnormal LCI and $S_{\text {cond }}$ in $47 \%$ and $53 \%$ of patients [88] despite spirometry being normal in the majority of patients (>90\%). LCI z-score was significantly inversely correlated with the $\mathrm{FEV}_{1}$ z-score even years after completion of treatment. 
The above-mentioned follow-up study in patients diagnosed with HP [88] also found $V^{\prime}{ }_{\mathrm{O}_{2}}$ peak to be in the normal range in the majority of patients $(>85 \%)$ at follow-up after treatment was finished, and demonstrated a significant correlation between $V^{\prime}{ }_{\mathrm{O}_{2} \text { peak }}$ and FVC.

\section{Storage disorders}

In an international cross-sectional study including 59 adult and paediatric patients with Niemann-Pick Type B (30 children aged 6-17 years), 53 had high-resolution computed tomography abnormalities suggestive of interstitial lung disease [90]. Spirometry was performed in 55 patients, showing reduced FVC in $47 \%$ and an abnormal $\mathrm{FEV}_{1} / \mathrm{FVC}$ ratio in $22 \%$. $T_{\mathrm{LCO}}$ was reduced in $79 \%$ of patients despite only $12 \%$ exhibiting respiratory symptoms. There was a significantly lower $T_{\mathrm{LCO}} \%$ pred in patients with a history of initial shortness of breath compared to those without. $6 \mathrm{MWT}$ was abnormal in only $5 \%$ of the patients. No follow-up studies have been reported.

\section{Rheumatological disorders}

There may be pulmonary involvement in the rheumatological disorders, the prevalence and severity depending on the underlying condition [91]. Secondary pulmonary involvement has been explored in several cross-sectional studies. We identified six studies reporting pulmonary function in children (range 13-40 patients) with systemic lupus erythematosus (SLE) [92-97]. All patients had abnormal spirometry, mostly restrictive, with reduced diffusing capacity, despite which many were asymptomatic. However, half of the studies in SLE found $T_{\mathrm{LCO}}$ was reduced in only a very few patients $[93,95,97]$ while the remainder found abnormal $T_{\mathrm{LCO}}$ values in more than half of the patients $[92,94,96]$. In one of the studies, $T_{\mathrm{LCO}}$ was related to the activity of systemic inflammatory processes and disease activity score [94] A CPET was conducted in 10 children with SLE [98]. $V^{\prime}{ }_{\mathrm{O}_{2} \text { peak }}$ was reduced in all patients and in $80 \%$ of patients the exercise endurance was below the second percentile compared to age- and sex-matched healthy controls. Muscle strength was reduced in the majority of patients and $40 \%$ had $<60 \%$ muscle mass for their age and sex. Unfortunately, the authors did not perform PFT and it is therefore not known whether the reduced $V^{\prime} \mathrm{O}_{2}$ peak was related to impaired lung function or impaired physical ability.

In one study in children with juvenile dermatomyositis [99], two studies in children with systemic sclerosis $[100,101]$ and one study including a mixture of different connective tissue diseases [102] demonstrated similar results with predominant varying degrees of restrictive spirometry in up to $50-60 \%$ of patients and also varying impairment in $T_{\mathrm{LCO}}$. However, in a large follow-up study including 51 patients treated for juvenile dermatomyositis [103] spirometry was normal in $82 \%$ of patients, and restrictive interstitial lung disease was only diagnosed in $8 \%$.

There were no differences in 6MWT performance in children with either systemic sclerosis or SLE, irrespective of whether there was pulmonary involvement [97, 104]. In children with systemic sclerosis, 6MWD was mostly influenced by myalgia. They had a higher incidence of lower extremity pain and shorter 6MWD compared to children with SLE and healthy controls. Only two (7\%) out of 28 paediatric SLE patients had a desaturation $>4 \%$ at the end of the test [97].

These studies underline the importance of regular lung function testing including spirometry and measurement of diffusing capacity in connective tissue diseases, even in those with no respiratory symptoms.

\section{PIBO}

Several studies using mostly spirometry and whole-body plethysmography in large cohorts of children from school age with PIBO [105-108] found moderate-to-severe obstructive lung function impairment (reduced $\mathrm{FEV}_{1}, \mathrm{FEV}_{1} / \mathrm{FVC}$ and flow at low lung volumes, with hyperinflation and markedly increased $R_{\mathrm{aw}}$ ) [105]. In a prospective study, 46 school-age children with $\mathrm{PIBO}$ who were followed up for a mean \pm SD $12.5 \pm 3.5$ years were found to have a persistent severe obstructive lung function with a decrease in z-score per year for $\mathrm{FEV}_{1}$, $\mathrm{FVC}$ and $\mathrm{FEV}_{1} / \mathrm{FVC}$ of $0.07,0.09$ and 0.04 , respectively [106]. A similar trend was documented in another small study of 11 school children with mean follow-up time of $\sim 10$ years with a decline of approximately $1 \%$ per year in $\mathrm{FEV}_{1}$, forced mid-expiratory flow at 25-75\% of FVC and $\mathrm{FEV}_{1} / \mathrm{FVC}$; FVC did not significantly change over time [107]. $T_{\mathrm{LCO}}$ was also moderately reduced in 10 out of 11 children at the time of diagnosis, with a median value of $55 \%$ pred while $T_{\mathrm{LCO}} / V_{\mathrm{A}}$ was preserved in all patients [107]. Impairment of diffusion capacity per se is not thought of as a dominant feature in this patient group and may be related to ventilation inhomogeneity due to severe obstruction/obliteration of the bronchioles, and this may lead to the reliability of the test results in these patients being affected [30].

Also, structural abnormalities in computed tomography scans performed within the first 3 years of life in children with PIBO showed a correlation between these early CT scores and spirometry measured years later (aged 8-15 years) in the same patients [108]. 
FOT was performed in 12 pre-school children (aged 3-5 years) with PIBO, 135 children with asthma and 35 nonatopic controls [109]. Resistance of respiratory system 5\% pred and respiratory system reactance 5\% pred were significantly higher in children with PIBO than in the asthma or normal control groups. There was no significant bronchodilator reversibility in the PIBO children.

MBW has been measured in two studies. GuR et al. [110] compared a group of 16 children and young adults with bronchiolitis obliterans (14 PIBO and two post burn) to a group of age- and sex-matched CF patients, and found LCI to be comparably elevated in the two patient groups. In addition, the LCI z-score correlated with $\mathrm{FEV}_{1}$ and $\mathrm{FVC}, \mathrm{z}$-scores and computed tomography scores using a modified Bhalla score. A recently published follow-up study in 15 children and young adults previously treated for post-infectious diffuse lung disease [111] revealed similar results, with abnormal z-scores for LCI and $\mathrm{FEV}_{1}$ in a high proportion of patients (80\% and 53\%, respectively) and with significant associations between $z L C I$ and $z F E V_{1}$.

Exercise capacity and lung function were evaluated in 20 PIBO patients [112]. 6MWD was significantly reduced compared to reference values but did not correlate with $V^{\prime}{ }_{\mathrm{O}_{2} \text { peak }}$ in maximal CPET. However, $6 \mathrm{MWD}$ was correlated with $\mathrm{FEV}_{1}, \mathrm{FVC}$ and residual volume/TLC and may be an acceptable alternative when CPET is not available.

16 patients (aged 10-23 years) diagnosed with PIBO performed cycle incremental CPET and lung function

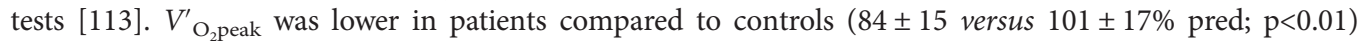
but did not correlate with $\mathrm{FEV}_{1}(\mathrm{r}=0.45 ; \mathrm{p}=0.09)$.

\section{Miscellaneous and unspecified interstitial lung disease conditions}

There were two small studies in children with sarcoidosis [114, 115]. Spirometry revealed a reduction of vital capacity in about half of the patients which correlated with respiratory symptoms. Additionally, at follow-up, improvement in spirometry correlated with better computed tomography scores [114]. In the larger $(n=21)$ of these studies [116], sarcoidosis patients had a reduced median $T_{\text {LCO }}(65 \%$ pred $)$ at initial assessment with normalisation after 6 months treatment.

There is one retrospective single-centre follow-up study in patients diagnosed between 2 weeks and 16 years of age with multisystemic Langerhans cell histiocytosis. Lung involvement documented clinically or radiological was present in $40 \%$ of the cohort [117]. Reduction of lung volumes and lung compliance were reported in $69.2 \%$ and $76.9 \%$, respectively. However, the iPFT methodology did not meet current standards and the results may be difficult to interpret.

KHIRANi et al. [118] used spirometry, $R_{\text {int }}$ and other tests in a cross-sectional study of nine school-age children and one infant ( 1.8 years) with a variety of chILD conditions and treatments. $R_{\text {int }}$ was abnormally increased in three out of nine patients, but not directly correlated to symptoms or diagnosis and vital capacity was severely reduced (mean $40 \%$ pred) in the seven children who could perform spirometry. Only one study published in 1982 documented tidal breathing indices (breathing pattern) and was therefore included despite being outside the time frame of our literature search [119]. In 14 children aged 4-16 years with various chILD conditions, RR and minute ventilation were increased whereas $t_{\mathrm{I}}$ was reduced. The ratio of $t_{I}$ to the total duration $\left(t_{\text {tot }}\right)$ of the respiratory cycle $\left(t_{\mathrm{I}} / t_{\text {tot }}\right)$ was also significantly reduced. They found a significant relationship between the $t_{\mathrm{I}}$ and the increase in lung elastance.

\section{Summary}

This is the first review describing pulmonary function testing in different chILD entities. The literature search revealed 48 publications from the past almost three decades. This underlines the large gaps in knowledge in lung function monitoring of chILD. Within the limited number of publications, spirometry was most utilised to assess disease severity and changes with time and treatment. Initial levels may be very low but near normalisation may be anticipated at follow-up in HP whereas data on long-term prognosis in other subgroups of chILD is still not known. Spirometry is widely available and should be used for basic monitoring from late preschool age, but the findings are not diagnostic of a specific chILD. There is a risk of misdiagnosis and overlap with much more common diseases like asthma in older children but finding restrictive changes on spirometry may be a helpful pointer to chILD. Adding measurements of lung volumes and $R_{\mathrm{aw}}$ by body plethysmography can help distinguish between primarily restrictive or obstructive diseases.

iPFT has potential for use in some of the less severe infant chILD conditions (e.g. pulmonary interstitial glycogenosis, NEHI and NEHI syndrome, as well as surfactant disorders manifesting early and surviving from infancy), to define typical lung function patterns and monitor changes over time and with treatment. In severe neonatal onset chILD conditions, which usually require ventilation or extracorporeal membrane oxygenation (e.g. alveolar capillary dysplasia, surfactant protein B mutations, ABCA3 homozygous or compound heterozygous null mutations), iPFT will not be feasible or be a useful guide in diagnosis or management. Infant whole-body plethysmography, measurement of passive respiratory tract mechanics 
and RVRTC were the techniques mostly used. However, more studies are needed to determine the utility of iPFT since very few centres in Europe perform routine iPFT and introducing the techniques has significant resource implications. This equally applies to tidal breathing indices, $R_{\text {int }}$ and FOT which, however, may be useful from the preschool age. However, what is clear is that we should be using objective measurements much more to monitor chILD; the fact chILD is an orphan disease should not mean second-rate monitoring.

$T_{\mathrm{LCO}}$ is a rapid and non-expensive PFT which is feasible from school age and should be performed at least at baseline in all such chILD patients. Currently, gas transfer data in chILD are based on only a few small studies in heterogeneous patient groups with a limited number of longitudinal measurements. MBW is rarely performed in chILD and LCI has not been used in any prospective studies. MBW supplements traditional PFT, such as spirometry, and has increased sensitivity; at least in CF pulmonary disease with normal $\mathrm{FEV}_{1}[120]$. Patients with severely obstructive spirometry will have an abnormal LCI, so MBW is not worth performing in addition. Furthermore, in the presence of obstruction, gas washout measurements take a very long time.

Studies of CPET in chILD are scanty but are included in this review because this test adds another dimension. The $6 \mathrm{MWT}$ is easy, cheap and safe to perform. Previous studies suggest $6 \mathrm{MWT}$ is useful in disease monitoring and probably as a prognostic marker in diseases; for example, the assessment for lung transplantation such as for transplant-free survival in childhood pulmonary arterial hypertension [121] and other lung diseases [122]. It has been shown to be a good predictive marker for death on the waiting list in adults with idiopathic pulmonary fibrosis awaiting lung transplantation [123]. $V_{\mathrm{O}_{2} \text { peak }}^{\prime}$ measurement is possible in specialised centres but is time and resource intensive.

Some PFT techniques have not been included in this review, mainly because experience in chILD is limited. We did not include spot and overnight oximetry and RR studies in this review; these are standardised measures and should be part of the management of all cases of chILD to assess any requirement for supplemental oxygen. Diffusing capacity for nitric oxide is a test with many similarities to $T_{\mathrm{LCO}}$ but may be more feasible than $T_{\mathrm{LCO}}$ in younger children due to the need for a shorter breath hold. A ERS SOP was published in 2017 [124] and both paediatric (5-18 years) [125] and adult [126] reference materials exist. The MBW method is attractive because it is feasible in all age groups including infants, and the use of MBW in chILD should be further explored, especially in young children, because little else is widely feasible in this age group. Further investigations are needed to understand whether there are any correlations between exercise testing and other lung function outcomes, clinical parameters or quality of life. The hypoxic challenge test could be useful in the future [127] as it may reflect subclinical disease in chILD. However, changes over time for the individual child seem to be the most important outcome as variability is seen in even healthy children [128].

In general, most published work consists of descriptive, cross-sectional single-centre studies with small numbers due to the rarity of the diseases. Details of the reported lung function data varied significantly and, especially in older studies, the different disease entities were often not specified. Follow-up studies are mostly in systemic diseases with secondary pulmonary involvement, mainly rheumatological; probably as children more frequently grow into adolescence and adulthood with these diseases, and diagnostic specificity and treatment has improved significantly in the past decades. Most studies are conducted in patients from school age and onwards, albeit many incident cases of chILD occur at a younger age [1].

The PFTs we have discussed are all well-established methods with published ERS/ATS consensus statements for standardised test performance in paediatric patients and commercially available equipment (table 1). However, for a large proportion of the studies, the SOP/guideline used was not specified in the publication and it was therefore impossible to conclude whether the technique was standardised or the report of outcomes acceptable. Not all techniques are widely available, but patients suspected of having chILD are usually referred to specialised centres for a diagnostic work-up. Age-related reference material is available for most techniques for the target age range, except for nitrogen MBW, but not all reference materials cover diverse ethnic groups. The methods are generally considered safe and without adverse effects or discomfort for the patient, but some iPFTs require sedation and in each case the patient's clinical condition and the value of the information must be balanced against the procedural risks. Patients with severe restrictive or obstructive ventilatory impairments may not have large enough lung volumes or tolerate breath hold for some manoeuvres, even if they are of an age to cooperate. Table 2 describes suggestions for the minimal indications for PFT in patients with chILD.

Limitations of this review include that only selected PFTs have been discussed, and only publications from 1990 and onwards were included. However, earlier publications long predate the classifications of chILD, and pulmonary function testing has changed dramatically from before this time $[1,2]$. Another limitation is the necessity of excluding studies with adult patients as well as children, other than one follow-up study in five patients with SFTPC mutations [80]. 
TABLE 2 Main clinical indications for testing lung function in children's interstitial lung disease (chILD)

Indication

Pulmonary function test

Diagnostics ${ }^{\#}$

Restrictive lung disease in older children? Low FEV 1 and FVC, $\mathrm{FEV}_{1} / \mathrm{FVC}$ ratio normal or high, low lung volumes

bstructive lung disease (PIBO suspected)? Low FEV 1 , FVC normal or low, $\mathrm{FEV}_{1} / \mathrm{FVC}$ ratio low, raised lung volumes and resistance Alveolar haemorrhage? Raised $D_{\mathrm{Lco}}$ NEHI? Obstructive RVRTC, raised lung volumes chILD with interstitial thickening/fibrosis or prominent involvement of pulmonary vasculature (e.g. hepatopulmonary syndrome)?

Disease monitoring Low $D_{\text {LCO }}$

Spirometry in older children

Recurrent pulmonary haemorrhage: increasing $D_{\mathrm{Lco}}$; progressive fibrosis: decreasing $D_{\mathrm{LCO}}$

Cardiopulmonary exercise testing

Monitoring extrapulmonary

Respiratory muscle weakness, e.g. in juvenile dermatomyositis: co-morbidities of chILD

lying and standing VC, MIP and MEP

FEV1: forced expiratory volume in $1 \mathrm{~s}$; FVC: forced vital capacity; PIBO: post-infectious bronchiolitis obliterans; $D_{\mathrm{Lco}}$ : diffusing capacity of the lung for carbon monoxide; NEHI: neuroendocrine cell hyperplasia of infancy; RVRTC: raised volume rapid thoracoabdominal compression; VC: vital capacity; MIP: maximum inspiratory pressure; MEP: maximum expiratory pressure. " : it is not possible to make specific pathological diagnoses from lung function testing, but it may be helpful to direct further diagnostic approach.

\section{Conclusion}

In summary, guidelines on chILD diagnosis recommend including PFTs [3, 129]. However, the existing literature on both diagnosis and follow-up and the added value of PFTs to clinical examination, radiology or other diagnostic testing is sparse and, in most cases, not disease specific. chILD is diverse and includes more than 200 different and heterogeneous conditions. There are some data to indicate that PFT may be useful in some stages of management of children with suspected chILD. PFTs help to distinguish obstructive and restrictive impairments, the latter thus suggesting chILD rather than much more common primary airway diseases. PFTs may be used for follow-up of patients with chILD. Clearly, the evidence gaps we have identified need to be addressed. The first prerequisite is to enrol all children with interstitial lung disease in national and/or international registries. All patients should regularly have lung function testing, but the tools will inevitably depend on the highly variable resources across Europe. Observational studies will inform guidelines into which tests are most sensitive in a disease-specific fashion. We must also beware of collecting data for its own sake, in particular if the techniques are resource-intensive or involve risk (e.g. sedation of a tachypnoeic child). Specifically, infant PFTs have yet to be shown to have added value to standard techniques in any chILD, but this should not preclude focussed explorations of their clinical role. As with adult ILD, it is highly unlikely that many if any specific diagnoses of chILD will be made in the physiology laboratory, but lung function techniques may well be used to place monitoring of treatment benefit on an objective footing.

An international approach and platforms like the chILD-EU registry and Enter chILD COST action (CA-16125) and other international research networks are essential if respiratory specialists are to fill the evidence gaps in the management of these rare, and often serious diseases.

Conflict of interest: A.M. Ring has nothing to disclose. J. Carlens has nothing to disclose. A. Bush has nothing to disclose. S. Castillo-Corullón has nothing to disclose. S. Fasola has nothing to disclose. M.P. Gaboli has nothing to disclose. M. Griese reports grants and personal fees from Boehringer-Ingelheim, outside the submitted work. V. Koucky reports non-financial support from Mylan Pharmaceuticals s.r.o., outside the submitted work. S. La Grutta has nothing to disclose. E. Lombardi reports personal fees from Boehringer-Ingelheim and grants from Restech, outside the submitted work. M. Proesmans has nothing to disclose. N. Schwerk has nothing to disclose. D. Snijders reports grants from Cost Action Ca16126 ENTeR-chILD, during the conduct of the study. K.G. Nielsen has nothing to disclose. F. Buchvald has nothing to disclose.

Support statement: The COST Action 16125 working group" Enter chILD" and this work was funded by the EU COST action for research and innovation network. Funding information for this article has been deposited with the Crossref Funder Registry. 


\section{References}

1 Deutsch GH, Young LR, Deterding RR, et al. Diffuse lung disease in young children: application of a novel classification scheme. Am J Respir Crit Care Med 2007; 176: 1120-1128.

2 Griese M, Irnstetter A, Hengst M, et al. Categorizing diffuse parenchymal lung disease in children. Orphanet $J$ Rare Dis 2015; 10: 122 .

3 Bush A, Cunningham S, de Blic J, et al. European protocols for the diagnosis and initial treatment of interstitial lung disease in children. Thorax 2015; 70: 1078-1084.

$4 \quad$ Clement A, Eber E. Interstitial lung diseases in infants and children. Eur Respir J 2008; 31: 658-666.

5 Stocks J, Godfrey S, Beardsmore C, et al. Plethysmographic measurements of lung volume and airway resistance. ERS/ATS Task Force on Standards for Infant Respiratory Function Testing. European Respiratory Society/ American Thoracic Society. Eur Respir J 2001; 17: 302-312.

6 Nguyen TT, Hoo AF, Lum S, et al. New reference equations to improve interpretation of infant lung function. Pediatr Pulmonol 2013; 48: 370-380.

7 Hulskamp G, Hoo AF, Ljungberg H, et al. Progressive decline in plethysmographic lung volumes in infants: physiology or technology? Am J Respir Crit Care Med 2003; 168: 1003-1009.

8 Gappa M, Colin AA, Goetz I, et al. Passive respiratory mechanics: the occlusion techniques. Eur Respir J 2001; 17: $141-148$.

9 Hanrahan JP, Brown RW, Carey VJ, et al. Passive respiratory mechanics in healthy infants. Effects of growth, gender, and smoking. Am J Respir Crit Care Med 1996; 154: 670-680.

10 The raised volume rapid thoracoabdominal compression technique. The Joint American Thoracic Society/ European Respiratory Society Working Group on Infant Lung Function. Am J Respir Crit Care Med 2000; 161: $1760-1762$.

11 Sly PD, Tepper R, Henschen M, et al. Tidal forced expirations. ERS/ATS Task Force on Standards for Infant Respiratory Function Testing. European Respiratory Society/American Thoracic Society. Eur Respir J 2000; 16: 741-748.

12 Jones M, Castile R, Davis S, et al. Forced expiratory flows and volumes in infants. Normative data and lung growth. Am J Respir Crit Care Med 2000; 161: 353-359.

13 Castile R, Filbrun D, Flucke R, et al. Adult-type pulmonary function tests in infants without respiratory disease. Pediatr Pulmonol 2000; 30: 215-227.

14 von Ungern-Sternberg BS, Trachsel D, Erb TO, et al. Forced expiratory flows and volumes in intubated and paralyzed infants and children: normative data up to 5 years of age. J Appl Physiol 2009; 107: 105-111.

15 Beydon N, Davis SD, Lombardi E, et al. An official American Thoracic Society/European Respiratory Society statement: pulmonary function testing in preschool children. Am J Respir Crit Care Med 2007; 175: 1304-1345.

16 Gaultier C, Perret L, Boule M, et al. Occlusion pressure and breathing pattern in healthy children. Respir Physiol 1981; 46: 71-80.

17 Carlsen KH, Lodrup Carlsen KC. Tidal breathing analysis and response to salbutamol in awake young children with and without asthma. Eur Respir J 1994; 7: 2154-2159.

18 Merkus PJ, Stocks J, Beydon N, et al. Reference ranges for interrupter resistance technique: the Asthma UK Initiative. Eur Respir J 2010; 36: 157-163.

19 Oostveen E, MacLeod D, Lorino H, et al. The forced oscillation technique in clinical practice: methodology, recommendations and future developments. Eur Respir J 2003; 22: 1026-1041.

20 Bickel S, Popler J, Lesnick B, et al. Impulse oscillometry: interpretation and practical applications. Chest 2014; 146: 841-847.

21 Wanger J, Clausen JL, Coates A, et al. Standardisation of the measurement of lung volumes. Eur Respir J 2005; 26: $511-522$.

22 Kirkby J, Stanojevic S, Welsh L, et al. Reference equations for specific airway resistance in children: the Asthma UK initiative. Eur Respir J 2010; 36: 622-629.

23 Zapletal A, Samanek M, Paul T. Lung function in children and adolescents: methods, reference values. Basel, Karger, 1987.

24 Polgar G, Promadhat V. Pulmonary function testing in children: techniques and standards. Philadelphia, Saunders, 1971.

25 Miller MR, Hankinson J, Brusasco V, et al. Standardisation of spirometry. Eur Respir J 2005; 26: 319-338.

26 Rosenthal M, Bain SH, Cramer D, et al. Lung function in white children aged 4 to 19 years: I -Spirometry. Thorax 1993; 48: 794-802.

27 Hankinson JL, Odencrantz JR, Fedan KB. Spirometric reference values from a sample of the general U.S. population. Am J Respir Crit Care Med 1999; 159: 179-187.

28 Quanjer PH, Stanojevic S, Cole TJ, et al. Multi-ethnic reference values for spirometry for the 3-95-yr age range: the global lung function 2012 equations. Eur Respir J 2012; 40: 1324-1343.

29 Praca ELL, Tiller CJ, Kisling JA, et al. An alternative method to measure the diffusing capacity of the lung for carbon monoxide in infants. Pediatr Pulmonol 2018; 53: 332-336.

30 Graham BL, Brusasco V, Burgos F, et al. 2017 ERS/ATS standards for single-breath carbon monoxide uptake in the lung. Eur Respir J 2017; 49: 1600016.

31 Koopman M, Zanen P, Kruitwagen CL, et al. Reference values for paediatric pulmonary function testing: the Utrecht dataset. Respir Med 2011; 105: 15-23.

32 Cotes JE, Chinn DJ, Quanjer PH, et al. Standardization of the measurement of transfer factor (diffusing capacity). Eur Respir J 1993; 6: Suppl. 16, 41-52.

33 Rosenthal M, Cramer D, Bain SH, et al. Lung function in white children aged 4 to 19 years: II -Single breath analysis and plethysmography. Thorax 1993; 48: 803-808.

34 Stam H, Beek AV, Grunberg K, et al. A rebreathing method to determine carbon monoxide diffusing capacity in children: reference values for 6- to 18-year-olds [corrected] and validation in adult volunteers. Pediatr Pulmonol 1998; 25: 205-212.

35 Stanojevic S, Graham BL, Cooper BG, et al. Official ERS technical standards: Global Lung Function Initiative reference values for the carbon monoxide transfer factor for Caucasians. Eur Respir J 2017; 50: 1700010 . 
Robinson PD, Goldman MD, Gustafsson PM. Inert gas washout: theoretical background and clinical utility in respiratory disease. Respiration 2009; 78: 339-355.

Robinson PD, Latzin P, Ramsey KA, et al. Preschool multiple-breath washout testing. An Official American Thoracic Society Technical Statement. Am J Respir Crit Care Med 2018; 197: e1-e19.

Fuchs SI, Eder J, Ellemunter H, et al. Lung clearance index: normal values, repeatability, and reproducibility in healthy children and adolescents. Pediatr Pulmonol 2009; 44: 1180-1185.

Anagnostopoulou P, Latzin P, Jensen R, et al. Normative data for multiple breath washout outcomes in schoolaged Caucasian children. Eur Respir J 2020; 55: 1901302.

Lum S, Stocks J, Stanojevic S, et al. Age and height dependence of lung clearance index and functional residual capacity. Eur Respir J 2013; 41: 1371-1377.

Narang I, Pike S, Rosenthal M, et al. Three-minute step test to assess exercise capacity in children with cystic fibrosis with mild lung disease. Pediatr Pulmonol 2003; 35: 108-113.

Jalili M, Nazem F, Sazvar A, et al. Prediction of maximal oxygen uptake by six-minute walk test and body mass index in healthy boys. J Pediatr 2018; 200: 155-159.

Nixon PA, Orenstein DM, Kelsey SF, et al. The prognostic value of exercise testing in patients with cystic fibrosis. N Engl J Med 1992; 327: 1785-1788.

Bruce RA, Blackmon JR, Jones JW, et al. Exercising testing in adult normal subjects and cardiac patients. Pediatrics 1963; 32: 742-756.

Turner DJ, Stick SM, Lesouef KL, et al. A new technique to generate and assess forced expiration from raised lung volume in infants. Am J Respir Crit Care Med 1995; 151: 1441-1450.

Turner DJ, Lanteri CJ, LeSouef PN, et al. Improved detection of abnormal respiratory function using forced expiration from raised lung volume in infants with cystic fibrosis. Eur Respir J 1994; 7: 1995-1999.

Katier N, Uiterwaal CS, de Jong BM, et al. Passive respiratory mechanics measured during natural sleep in healthy term neonates and infants up to 8 weeks of life. Pediatr Pulmonol 2006; 41: 1058-1064.

Bates JH, Schmalisch G, Filbrun D, et al. Tidal breath analysis for infant pulmonary function testing. ERS/ATS Task Force on Standards for Infant Respiratory Function Testing. European Respiratory Society/American Thoracic Society. Eur Respir J 2000; 16: 1180-1192.

Ranganathan SC, Goetz I, Hoo AF, et al. Assessment of tidal breathing parameters in infants with cystic fibrosis. Eur Respir J 2003; 22: 761-766.

Hulskamp G, Pillow JJ, Dinger J, et al. Lung function tests in neonates and infants with chronic lung disease of infancy: functional residual capacity. Pediatr Pulmonol 2006; 41: 1-22.

Lum S, Hulskamp G, Merkus $\mathrm{P}$, et al. Lung function tests in neonates and infants with chronic lung disease: forced expiratory maneuvers. Pediatr Pulmonol 2006; 41: 199-214.

Gappa M, Pillow JJ, Allen J, et al. Lung function tests in neonates and infants with chronic lung disease: lung and chest-wall mechanics. Pediatr Pulmonol 2006; 41: 291-317.

Linnane BM, Hall GL, Nolan G, et al. Lung function in infants with cystic fibrosis diagnosed by newborn screening. Am J Respir Crit Care Med 2008; 178: 1238-1244.

Nguyen TT, Thia LP, Hoo AF, et al. Evolution of lung function during the first year of life in newborn screened cystic fibrosis infants. Thorax 2014; 69: 910-917.

Ranganathan SC, Stocks J, Dezateux C, et al. The evolution of airway function in early childhood following clinical diagnosis of cystic fibrosis. Am J Respir Crit Care Med 2004; 169: 928-933.

van der Gugten AC, Uiterwaal CS, van Putte-Katier N, et al. Reduced neonatal lung function and wheezing illnesses during the first 5 years of life. Eur Respir J 2013; 42: 107-115.

Lombardi E, Sly PD, Concutelli G, et al. Reference values of interrupter respiratory resistance in healthy preschool white children. Thorax 2001; 56: 691-695.

Merkus PJ, Arets HG, Joosten T, et al. Measurements of interrupter resistance: reference values for children 3-13 yrs of age. Eur Respir J 2002; 20: 907-911.

McKenzie SA, Chan E, Dundas I, et al. Airway resistance measured by the interrupter technique: normative data for 2-10 year olds of three ethnicities. Arch Dis Child 2002; 87: 248-251.

Schwartz DA, Van Fossen DS, Davis CS, et al. Determinants of progression in idiopathic pulmonary fibrosis. Am J Respir Crit Care Med 1994; 149: 444-449.

Clark EH, Woods RL, Hughes JM. Effect of blood transfusion on the carbon monoxide transfer factor of the lung in man. Clin Sci Mol Med 1978; 54: 627-631.

Graham BL, Mink JT, Cotton DJ. Effects of increasing carboxyhemoglobin on the single breath carbon monoxide diffusing capacity. Am J Respir Crit Care Med 2002; 165: 1504-1510.

Greening AP, Hughes JM. Serial estimations of carbon monoxide diffusing capacity in intrapulmonary haemorrhage. Clin Sci 1981; 60: 507-512.

Collard P, Njinou B, Nejadnik B, et al. Single breath diffusing capacity for carbon monoxide in stable asthma. Chest 1994; 105: 1426-1429.

Stewart RI. Carbon monoxide diffusing capacity in asthmatic patients with mild airflow limitation. Chest 1988; 94: 332-336.

Fitting JW. Transfer factor for carbon monoxide: a glance behind the scene. Swiss Med Wkly 2004; 134: 413-418. Castillo A, Llapur CJ, Martinez T, et al. Measurement of single breath-hold carbon monoxide diffusing capacity in healthy infants and toddlers. Pediatr Pulmonol 2006; 41: 544-550.

Robinson PD, Latzin P, Verbanck S, et al. Consensus statement for inert gas washout measurement using multiple- and single-breath tests. Eur Respir J 2013; 41: 507-522.

Davies G, Aurora P. The use of multiple breath washout for assessing cystic fibrosis in infants. Expert Rev Respir Med 2017; 11: 21-28.

Horsley A, Wild JM. Ventilation heterogeneity and the benefits and challenges of multiple breath washout testing in patients with cystic fibrosis. Paediatr Respir Rev 2015; 16: Suppl. 1, 15-18.

Gustafsson PM, De Jong PA, Tiddens HA, et al. Multiple-breath inert gas washout and spirometry versus structural lung disease in cystic fibrosis. Thorax 2008; 63: 129-134.

ATS statement: guidelines for the six-minute walk test. Am J Respir Crit Care Med 2002; 166: 111-117. Geiger R, Strasak A, Treml B, et al. Six-minute walk test in children and adolescents. J Pediatr 2007; 150: 395-399. 
ERS Task Force on Standardization of Clinical Exercise Testing. Clinical exercise testing with reference to lung diseases: indications, standardization and interpretation strategies. Eur Respir J 1997; 10: 2662-2689.

ATS/ACCP. ATS/ACCP Statement on cardiopulmonary exercise testing. Am J Respir Crit Care Med 2003; 167: 211-277.

Godfrey S. Methods of measuring the response to exercise in children. Exercise testing in children: applications in health and disease. London, W.B. Saunders Company Ltd, 1974.

Takken T, Bongers BC, van Brussel M, et al. Cardiopulmonary exercise testing in pediatrics. Ann Am Thorac Soc 2017; 14: Suppl. 1, S123-S128.

Ten Harkel AD, Takken T, Van Osch-Gevers M, et al. Normal values for cardiopulmonary exercise testing in children. Eur J Cardiovasc Prev Rehabil 2011; 18: 48-54.

Hevroni A, Goldman A, Springer C. Infant pulmonary function testing in chronic pneumonitis of infancy due to surfactant protein C mutation. Pediatr Pulmonol 2015; 50: E17-E23.

Avital A, Godfrey S, Maayan C, et al. Chloroquine treatment of interstitial lung disease in children. Pediatr Pulmonol 1994; 18: 356-360.

Avital A, Hevroni A, Godfrey S, et al. Natural history of five children with surfactant protein C mutations and interstitial lung disease. Pediatr Pulmonol 2014; 49: 1097-1105.

Doan ML, Guillerman RP, Dishop MK, et al
mutations in children. Thorax 2008; 63: 366-373.

Chical, radiological and pathological features of $\mathrm{ABCA} 3$

Ehsan Z, Montgomery GS, Tiller C, et al. An infant with pulmonary interstitial glycogenosis: clinical improvement is associated with improvement in the pulmonary diffusion capacity. Pediatr Pulmonol 2014; 49: E17-E20.

Young LR, Brody AS, Inge TH, et al. Neuroendocrine cell distribution and frequency distinguish neuroendocrine cell hyperplasia of infancy from other pulmonary disorders. Chest 2011; 139: 1060-1071.

Lukkarinen H, Pelkonen A, Lohi J, et al. Neuroendocrine cell hyperplasia of infancy: a prospective follow-up of nine children. Arch Dis Child 2013; 98: 141-144.

Kerby GS, Wagner BD, Popler J, et al. Abnormal infant pulmonary function in young children with neuroendocrine cell hyperplasia of infancy. Pediatr Pulmonol 2013; 48: 1008-1015.

hypersensitivity pneumonitis. Pediatr Pulmonol 2011; 46: 1098-1107.

functional outcome in children with Sisman Y, Buchvald F, Blyme AK, et al. Pulmonary function and fitness years after treatment for hypersensitivity pneumonitis during childhood. Pediatr Pulmonol 2016; 51: 830-837.

Griese M, Haug M, Hartl D, et al. Hypersensitivity pneumonitis: lessons for diagnosis and treatment of a rare entity in children. Orphanet J Rare Dis 2013; 8: 121.

McGovern MM, Wasserstein MP, Giugliani R, et al. A prospective, cross-sectional survey study of the natural history of Niemann-Pick disease type B. Pediatrics 2008; 122: e341-e349.

Ha YJ, Lee YJ, Kang EH. Lung involvements in rheumatic diseases: update on the epidemiology, pathogenesis, clinical features, and treatment. Biomed Res Int 2018; 2018: 6930297.

Abdulla E, Al-Zakwani I, Baddar S, et al. Extent of subclinical pulmonary involvement in childhood onset systemic lupus erythematosus in the Sultanate of Oman. Oman Med J 2012; 27: 36-39.

Trapani S, Camiciottoli G, Ermini M, et al. Pulmonary involvement in juvenile systemic lupus erythematosus: a study on lung function in patients asymptomatic for respiratory disease. Lupus 1998; 7: 545-550.

Cerveri I, Fanfulla F, Ravelli A, et al. Pulmonary function in children with systemic lupus erythematosus. Thorax 1996; 51: 424-428.

Al-Abbad AJ, Cabral DA, Sanatani S, et al. Echocardiography and pulmonary function testing in childhood onset systemic lupus erythematosus. Lupus 2001; 10: 32-37.

Delgado EA, Malleson PN, Pirie GE, et al. The pulmonary manifestations of childhood onset systemic lupus erythematosus. Semin Arthritis Rheum 1990; 19: 285-293.

Veiga CS, Coutinho DS, Nakaie CM, et al. Subclinical pulmonary abnormalities in childhood-onset systemic lupus erythematosus patients. Lupus 2016; 25: 645-651.

SLE. Pediatr Rheumatol Online J 2016; 14: 50. Trapani S, Camiciottoli G, Vierucci A, et al. Pulmonary involvement in juvenile dermatomyositis: a two-year longitudinal study. Rheumatology (Oxford) 2001; 40: 216-220.

Panigada S, Ravelli A, Silvestri M, et al. HRCT and pulmonary function tests in monitoring of lung involvement in juvenile systemic sclerosis. Pediatr Pulmonol 2009; 44: 1226-1234.

Garty BZ, Athreya BH, Wilmott R, et al. Pulmonary functions in children with progressive systemic sclerosis. Pediatrics 1991; 88: 1161-1167.

Cerveri I, Bruschi C, Ravelli A, et al. Pulmonary function in childhood connective tissue diseases. Eur Respir J 1992; 5: 733-738.

Mathiesen PR, Buchvald F, Nielsen KG, et al. Pulmonary function and autoantibodies in a long-term follow-up of juvenile dermatomyositis patients. Rheumatology (Oxford) 2014; 53: 644-649.

Koker O, Adrovic A, Sahin S, et al. Evaluation of six-minute walk test in juvenile systemic sclerosis. Rheumato Int 2019; 39: 293-300.

Mattiello R, Vidal PC, Sarria EE et al Evaluating bronchodilator response in pediatric patients with post-infectious bronchiolitis obliterans: use of different criteria for identifying airway reversibility. J Bras Pneumol 2016; 42: 174-178.

6 Colom AJ, Maffey A, Garcia Bournissen F, et al. Pulmonary function of a paediatric cohort of patients with postinfectious bronchiolitis obliterans. A long term follow-up. Thorax 2015; 70: 169-174.

Cazzato S, Poletti V, Bernardi F, et al. Airway inflammation and lung function decline in childhood post-infectious bronchiolitis obliterans. Pediatr Pulmonol 2008; 43: 381-390.

Mattiello R, Mallol J, Fischer GB, et al. Pulmonary function in children and adolescents with postinfectious bronchiolitis obliterans. J Bras Pneumol 2010; 36: 453-459.

Lee E, Yoon J, Cho HJ, et al. Respiratory reactance in children aged three to five years with postinfectious bronchiolitis obliterans is higher than in those with asthma. Acta Paediatr 2017; 106: 81-86. 
Gur M, Yaacoby-Bianu K, Ilivitzki A, et al. Lung Clearance Index (LCI) in patients with bronchiolitis obliterans: a preliminary report and comparison to cystic fibrosis patients. Lung 2016; 194: 1007-1013.

111 Sisman Y, Buchvald FF, Ring AM, et al. Long-term lung function and exercise capacity in postinfectious chILD. Pediatr Allergy Immunol Pulmonol 2019; 32: 4-11.

112 Mattiello R, Sarria EE, Stein R, et al. Functional capacity assessment in children and adolescents with post-infectious bronchiolitis obliterans. J Pediatr 2008; 84: 337-343.

113 Frohlich LF, Vieira PJ, Teixeira PJ, et al. Exercise capacity in adolescent and adult patients with post infectious bronchiolitis obliterans. Pediatr Pulmonol 2014; 49: 911-918.

114 Sileo C, Epaud R, Mahloul M, et al. Sarcoidosis in children: HRCT findings and correlation with pulmonary function tests. Pediatr Pulmonol 2014; 49: 1223-1233.

115 Hoffmann AL, Milman N, Byg KE. Childhood sarcoidosis in Denmark 1979-1994: incidence, clinical features and laboratory results at presentation in 48 children. Acta Paediatr 2004; 93: 30-36.

116 Baculard A, Blanc N, Boule M, et al. Pulmonary sarcoidosis in children: a follow-up study. Eur Respir J 2001; 17: 628-635.

117 Ha SY, Helms P, Fletcher M, et al. Lung involvement in Langerhans' cell histiocytosis: prevalence, clinical features, and outcome. Pediatrics 1992; 89: 466-469.

118 Khirani S, Nathan N, Ramirez A, et al. Work of breathing in children with diffuse parenchymal lung disease. Respir Physiol Neurobiol 2015; 206: 45-52.

119 Gaultier C, Perret L, Boule M, et al. Control of breathing in children with interstitial lung disease. Pediatr Res 1982; 16: 779-783.

120 Perrem L, Rayment JH, Ratjen F. The lung clearance index as a monitoring tool in cystic fibrosis: ready for the clinic? Curr Opin Pulm Med 2018; 24: 579-585.

121 Douwes JM, Hegeman AK, van der Krieke MB, et al. Six-minute walking distance and decrease in oxygen saturation during the six-minute walk test in pediatric pulmonary arterial hypertension. Int J Cardiol 2016; 202: 34-39.

122 Yimlamai D, Freiberger DA, Gould A, et al. Pretransplant six-minute walk test predicts peri- and post-operative outcomes after pediatric lung transplantation. Pediatr Transplant 2013; 17: 34-40.

123 Lederer DJ, Arcasoy SM, Wilt JS, et al. Six-minute-walk distance predicts waiting list survival in idiopathic pulmonary fibrosis. Am J Respir Crit Care Med 2006; 174: 659-664.

124 Zavorsky GS, van der Lee I. Can the measurement of pulmonary diffusing capacity for nitric oxide replace the measurement of pulmonary diffusing capacity for carbon monoxide? Respir Physiol Neurobiol 2017; 241: 9-16.

125 Thomas A, Hanel B, Marott JL, et al. The single-breath diffusing capacity of CO and NO in healthy children of European descent. PLoS One 2014; 9: e113177.

126 Munkholm M, Marott JL, Bjerre-Kristensen L, et al. Reference equations for pulmonary diffusing capacity of carbon monoxide and nitric oxide in adult Caucasians. Eur Respir J 2018; 52: 1500677.

127 Balfour-Lynn IM. Hypoxic challenge test for airflight in children with respiratory disease. Paediatr Respir Rev 2017; 21: 62-64.

128 Kobbernagel HE, Nielsen KG, Hanel B. Hypoxic challenge test applied to healthy children: influence of body positions and exertion on pulse oximetric saturation. Arch Dis Child 2013; 98: 602-606.

129 Kurland G, Deterding RR, Hagood JS, et al. An official American Thoracic Society clinical practice guideline: classification, evaluation, and management of childhood interstitial lung disease in infancy. Am J Respir Crit Care Med 2013; 188: 376-394. 